\title{
Squalene and Noncholesterol Sterols in Serum and Lipoproteins of Children with and without Familial Hypercholesterolemia
}

\author{
ANNA KETOMÄKI, HELENA GYLLING, MARTTI A. SIIMES, ALPO VUORIO, AND \\ TATU A. MIETTINEN
}

Division of Internal Medicine, Department of Medicine and Biomedicine [A.K., A.V., T.A.M.], Hospital for

Children and Adolescents [M.A.S.], University of Helsinki, Helsinki, and Department of Clinical Nutrition, University of Kuopio and Kuopio University Hospital, Kuopio [H.G.], Finland

\section{ABSTRACT}

\begin{abstract}
Squalene and noncholesterol sterols, e.g. lathosterol and plant sterols, the respective markers of cholesterol synthesis and absorption, are transported with cholesterol in serum lipoproteins. Their concentrations and ratios to cholesterol in serum and lipoproteins have not been carefully compared, especially in children and in marked hypercholesterolemia. Thus, we measured these variables with gas-liquid chromatography in 18 children with and 29 without familial hypercholesterolemia, all aged 5-17 y. Concentrations of most noncholesterol sterols were higher in serum, LDL, and intermediate density lipoprotein in the children with than those without familial hypercholesterolemia. Despite accumulation of noncholesterol sterols mainly in LDL (75\% in familial hypercholesterolemia and $55 \%$ in non-familial hypercholesterolemia, $p<0.001$ ), their ratios were mostly sim-
\end{abstract}

ilar in serum and lipoproteins of the two groups. The ratios of squalene and lathosterol were higher in VLDL and intermediate density lipoprotein, whereas in LDL that of lathosterol was lower than the respective serum values in both groups. Absorption marker sterol ratios were highest in HDL in both groups. Thus, even though the ratios of noncholesterol sterols to cholesterol in serum reflect, in general, synthesis and absorption of cholesterol, their ratios in different lipoproteins could give additional information of cholesterol metabolism. (Pediatr Res 53: 648-653, 2003)
Abbreviations
FH, familial hypercholesterolemia
IDL, intermediate density lipoprotein

The deranged catabolism of apo B containing LDL increases serum cholesterol levels in FH (1), even already at birth (2), resulting in development of arterial atherosclerotic lesions already at the ages of 3-19 y $(3,4)$. In addition to cholesterol, other minor sterols, called noncholesterol sterols, and squalene are also carried by serum lipoproteins. The cholesterol precursors squalene, lanosterol and other methyl sterols, and demethyl sterols $\left(\Delta^{8}\right.$-cholestenol, desmosterol, and lathosterol) reflect cholesterol synthesis (5-7), whereas plant sterols, campesterol and sitosterol, and cholestanol, a metabolite of cholesterol, reflect the efficiency of cholesterol absorption in normal and hyperlipidemic populations $(8-10)$, including heterozygous adults with FH (11). The values of serum noncholesterol sterols and squalene are, in general, standardized and

Received November 2, 2001; accepted September 12, 2002.

Correspondence: Tatu A. Miettinen, M.D., Division of Internal Medicine, Department of Medicine, University of Helsinki, P.O. Box 340, FIN-00029 HUS, Finland; e-mail: tatu.a.miettinen@helsinki.fi

Supported by The Finnish Medical Society Duodecim, Research Foundation of Orion Corporation, The Paavo Nurmi Foundation, The Paulo Foundation, and Helsinki University Central Hospital.

DOI: 10.1203/01.PDR.0000055771.28409.40 expressed as ratios to cholesterol (5) to eliminate the influence of varying cholesterol concentrations between different individuals as well as different lipoproteins. However, it is not known how exactly the serum noncholesterol sterol to cholesterol ratios are related to the respective ratios in different lipoproteins, especially in healthy children and those with FH. The measurement of the sterols in lipoproteins are expected to give more accurate information on the release of cholesterol precursors from liver into the circulation and on the reverse traffic mechanism of sterols from tissues through HDL. Thus, the aim of the present study was to investigate serum and lipoprotein noncholesterol sterol concentrations in markedly hypercholesterolemic children and in controls, and to compare the ratios of sterols to cholesterol in the different lipoproteins and relate them to the respective ratios in the serum. Accordingly, the study population was chosen to comprise children with genetically diagnosed heterozygous FH and healthy subjects of similar age.

\section{METHODS}

Subjects. The study population consisted of 47 children aged $5-16$ y ( 24 boys and 23 girls) who either had a relative with 
clinically or genetically documented $\mathrm{FH}$, or were themselves patients at the Outpatient Lipid Clinics of the Hospital for Children and Adolescents, University of Helsinki (Table 1). The subjects were divided into FH $(n=18)$ and non-FH $(n=$ 29) by DNA analysis characterizing the four most frequent Finnish LDL receptor mutations; FH-Helsinki (FH-Hki; $n=$ 11), FH-North-Karelia (FH-NK; $n=5)$, FH-Turku $(n=2)$, and none with FH-Pori (12-14). Serum total cholesterol values were $<5.0 \mathrm{mM}$ in the non-FH group. Diabetes and hypothyroidism were excluded by analyzing blood glucose and TSH levels. The possible use of plant stanol or sterol ester spread was ceased at least $3 \mathrm{wk}$ before entry to the study. During the study, the subjects continued their normal habitual diet without any hypolipidemic treatment including plant stanol and sterol ester spreads. One girl was a smoker and another one occasionally used antihistamines. Informed consent was obtained from the parents and also from the children older than $12 \mathrm{y}$ of age. The study protocol was approved by the Ethics Committee of the Children's Hospital, University of Helsinki.

Study design. The subjects visited the outpatient clinic once, and after fasting for at least $4 \mathrm{~h}$, a blood sample was drawn (5-15 mL, according to the patient's age). A routine medical examination, including puberty staging (15), automatic blood pressure measurement, and clinical examination of the Achilles tendons, was performed in 16 children with $\mathrm{FH}$ and in all control subjects.

Methods. DNA was isolated from the venous blood, and the analyses for FH-Hki, FH-NK, FH-Turku, and FH-Pori were carried out using the PCR technique $(14,16)$. Lipoproteins were separated by ultracentrifugation into the following density fractions: $\mathrm{VLDL}, \mathrm{d}<1.006 \mathrm{~g} / \mathrm{mL} ; \mathrm{IDL}, \mathrm{d}=1.006-1.019$ $\mathrm{g} / \mathrm{mL} ; \mathrm{LDL}, \mathrm{d}=1.019-1.063 \mathrm{~g} / \mathrm{mL}$; and HDL, $\mathrm{d}=1.063$ $1.210 \mathrm{~g} / \mathrm{mL}$. Total and free cholesterol, phospholipids, and serum triglycerides were measured by enzymatic color reactions with commercial kits (total cholesterol: CHOD-PAP,

Table 1. Characteristics of the study population*

\begin{tabular}{|c|c|c|}
\hline Variables & $\begin{array}{c}\mathrm{FH}_{\dagger}^{\dagger} \\
(n=18)\end{array}$ & $\begin{array}{l}\text { Non-FH }+ \\
(n=29)\end{array}$ \\
\hline Age (y) & $11.1 \pm 0.8$ & $11.2 \pm 0.6$ \\
\hline $\operatorname{Sex}(\mathrm{M} / \mathrm{F})$ & $10 / 8$ & $14 / 15$ \\
\hline Height $(\mathrm{cm})$ & $144.7 \pm 4.3(n=16)$ & $146.0 \pm 3.3$ \\
\hline Weight $(\mathrm{kg})$ & $39.0 \pm 3.7(n=16)$ & $40.4 \pm 3.0$ \\
\hline Body mass index $\left(\mathrm{kg} / \mathrm{m}^{2}\right)$ & $17.9 \pm 0.9(n=16)$ & $18.1 \pm 0.7$ \\
\hline Relative height (SD) & $0.3 \pm 0.2(n=16)$ & $0.2 \pm 0.2$ \\
\hline Height weight (\%) & $102.8 \pm 4.4(n=16)$ & $102.2 \pm 2.9$ \\
\hline Blood pressure $(\mathrm{mm} \mathrm{Hg})$ & $121 \pm 4 / 64 \pm 2(n=16)$ & $118 \pm 3 / 66 \pm 2$ \\
\hline Heart rate (beats/min) & $76 \pm 4(n=16)$ & $76 \pm 2$ \\
\hline Blood glucose (mM) & $5.2 \pm 0.1$ & $5.2 \pm 0.1$ \\
\hline Serum insulin $(\mathrm{mU} / \mathrm{L})$ & $9.1 \pm 2.6$ & $6.6 \pm 0.5$ \\
\hline Serum SHBG (nM) & $70.1 \pm 7.2$ & $72.9 \pm 6.6$ \\
\hline Apo E-2 & 1 & 4 \\
\hline Apo E-3 & 12 & 17 \\
\hline Apo E-4 & 5 & 8 \\
\hline
\end{tabular}

* Values are mean \pm SEM.

$\dagger$ FH are heterozygous for familial hypercholesterolemia by DNA analyses for LDL receptor mutations FH-Helsinki, FH-North Karelia, FH-Turku, and FH-Pori.

$\ddagger$ Non-FH have total cholesterol $<5.0 \mathrm{mM}$ and are negative for the four DNA analyses.

SHBG, sex hormone binding globulin. triglycerides: GPO-PAP, Roche, Basel, Switzerland; phospholipids:phospholipase D choline-oxidase PAP, Wako Chemicals, Neuss, Germany; free cholesterol: CHOD-PAP, Boehringer-Mannheim, Mannheim, Germany). Serum TSH was analyzed by our hospital laboratory with a chemiluminometric method. Blood glucose was measured with a commercial kit using glucose dehydrogenase method (Roche), serum insulin by RIA (Pharmacia \& Upjohn, Uppsala, Sweden), and sex hormone binding globulin by commercial kits (Wallac, Turku, Finland).

Cholesterol and cholesterol precursors, squalene, $\Delta^{8}$ cholestenol, desmosterol, and lathosterol (precursor sterols called synthesis markers of cholesterol), and cholestanol and plant sterols, campesterol and sitosterol (three sterols called absorption markers of cholesterol) were determined from serum and lipoproteins by gas-liquid chromatography on a 50 -m-long capillary column (Ultra-1; Hewlett-Packard, Wilmington, DE, U.S.A.) (17, 18). The values are expressed as concentrations (micrograms per deciliter) or as ratios defined as the concentration of particular sterol (in millimoles $\times 100$ ) to the concentration of cholesterol in moles to eliminate the effects of different transport protein concentrations on the noncholesterol sterol value. No recovery corrections were made for ultracentrifuge fractions. The lipoprotein squalene values were obtained only from $14 \mathrm{FH}$ and 24 non-FH children.

The apo E phenotype was determined electrophoretically by isoelectric focusing from serum samples (19). Subjects with phenotypes E2/2, E3/2, and E4/2 were combined and called apo E-2 group, those with E3/3 were called apo E-3, and those with $\mathrm{E} 4 / 3$ or E4/4 as apo E-4. The mean serum lipid and sterol values were calculated for apo E-4 versus the other apo E phenotypes.

Relative height was expressed as the deviation from the mean height of Finnish children of the same age, and relative weight was expressed as a percentage of the weight of children of the same height.

Statistical significances between the groups were tested with one-way ANOVA, two-sided $t$ test, and the $\chi^{2}$ test. The differences between the lipoprotein sterols were tested with the paired $t$ test. Correlation coefficients were calculated with Pearson's product moment correlation. When the distribution of a variable was skewed, logarithmic transformations were performed. A $p$ value $<0.05$ was considered significant, and data are reported as mean \pm SEM.

\section{RESULTS}

Characteristics of the study population. Age, sex, height, weight, body mass index, relative height and weight, blood pressure, blood glucose, serum concentrations of insulin and sex hormone binding globulin, and apo E phenotype distributions were similar in the subjects with or without FH (Table 1). No Achilles tendon xanthomas were found.

Demographic variables were similar in FH girls and boys, but the girls without $\mathrm{FH}$ were older $(12.5 \pm 0.7$ versus $9.8 \pm$ $0.9 \mathrm{y})$, taller $(154 \pm 3.8$ versus $138 \pm 4.8 \mathrm{~cm})$, and heavier $(47.1 \pm 4.2$ versus $33.2 \pm 3.5 \mathrm{~kg})$ than the boys $(p<0.05$ for all differences). 
Nine subjects (six boys, three girls) with FH and 12 (three boys, nine girls) without FH had reached pubertal development. In addition to age, the height and weight and the systolic and diastolic blood pressures were higher in the pubertal than in the prepubertal boys ( $p<0.05$ for all differences). In the pubertal girls, the systolic blood pressure was higher than in the prepubertal girls but only in the children without FH.

Serum lipids. The concentrations of serum total cholesterol and phospholipids, and those of LDL cholesterol, triglycerides, and phospholipids were higher and the HDL triglycerides and phospholipids lower in the children with $\mathrm{FH}$ than in those without FH (Table 2). The serum lipid levels were not affected by sex, prepubertal or postpubertal stage, or LDL receptor mutations. The percentage of esterified cholesterol was higher in IDL and HDL in the subjects with FH than in those without $\mathrm{FH}$.

Squalene and noncholesterol sterol distribution in lipoproteins. In the blood of the children with $\mathrm{FH}, 70-77 \%$ of the cholesterol (see footnote to Table 2) and noncholesterol sterols were in LDL, $16-24 \%$ in HDL, $2.3-3.6 \%$ in VLDL, and $1.5-2.2 \%$ in IDL (Fig. 1). The respective findings in the reference subjects were $52-57 \%$ of cholesterol and noncholesterol sterols in LDL ( $p<0.001$ versus $\mathrm{FH}), 32-40 \%$ in HDL ( $p<0.001$ versus $\mathrm{FH}), 4.3-6.4 \%$ in VLDL $(p<0.05$ versus $\mathrm{FH})$, and $1.7-3.1 \%$ in IDL $(p<0.05$ versus $\mathrm{FH})$. With the

Table 2. Serum and lipoprotein lipids $\uparrow$

\begin{tabular}{lll}
\hline \multicolumn{1}{c}{ Variables } & \multicolumn{1}{c}{$\begin{array}{c}\text { FH } \\
(n=18)\end{array}$} & $\begin{array}{c}\text { Non-FH§ } \\
(n=29)\end{array}$ \\
\hline Serum & & \\
Cholesterol & $7.47 \pm 0.33$ & $4.20 \pm 0.09^{* *}$ \\
Esterification \% & $73.6 \pm 0.6$ & $73.7 \pm 0.2$ \\
Triglycerides & $0.84 \pm 0.06$ & $0.87 \pm 0.08$ \\
Phospholipids & $3.05 \pm 0.14$ & $2.34 \pm 0.04^{* * *}$ \\
VLDL & & \\
Cholesterol & $0.18 \pm 0.03$ & $0.21 \pm 0.03$ \\
Esterification \% & $60.7 \pm 4.0$ & $56.8 \pm 3.1$ \\
Triglycerides & $0.36 \pm 0.05$ & $0.47 \pm 0.07$ \\
Phospholipids & $0.12 \pm 0.02$ & $0.15 \pm 0.02$ \\
IDL & & \\
Cholesterol & $0.11 \pm 0.02$ & $0.07 \pm 0.01$ \\
Esterification \% & $68.8 \pm 2.7$ & $59.9 \pm 3.1 *$ \\
Triglycerides & $0.06 \pm 0.004$ & $0.06 \pm 0.003$ \\
Phospholipids & $0.05 \pm 0.01$ & $0.04 \pm 0.002$ \\
LDL & & \\
Cholesterol & $5.47 \pm 0.29$ & $2.20 \pm 0.10^{* * *}$ \\
Esterification \% & $71.5 \pm 1.0$ & $70.5 \pm 0.3$ \\
Triglycerides & $0.24 \pm 0.02$ & $0.15 \pm 0.01^{* * *}$ \\
Phospholipids & $1.59 \pm 0.1$ & $0.70 \pm 0.03^{* * *}$ \\
HDL & & \\
Cholesterol & $1.23 \pm 0.07$ & $1.33 \pm 0.04$ \\
Esterification \% & $82.8 \pm 0.7$ & $80.8 \pm 0.3^{*}$ \\
Triglycerides & $0.11 \pm 0.01$ & $0.13 \pm 0.01^{*}$ \\
Phospholipids & $1.05 \pm 0.05$ & $1.23 \pm 0.03^{* *}$ \\
\hline
\end{tabular}

$\dagger$ Values are mean \pm SEM (in $\mathrm{mM}$ ).

$\ddagger$ FH are heterozygous for familial hypercholesterolemia by DNA diagnoses.

$\S$ Non-FH have total cholesterol $<5.0 \mathrm{mM}$ and are negative for the four Finnish FH mutations.

I Respective \% distribution of cholesterol in VLDL, IDL, LDL, and HDL were $2,1,73$, and $16 \%$ in $\mathrm{FH}$, and $5,2,52$, and $32 \%$ in non-FH.

$* p<0.05 ; * * p<0.01 ; * * * p<0.001$.

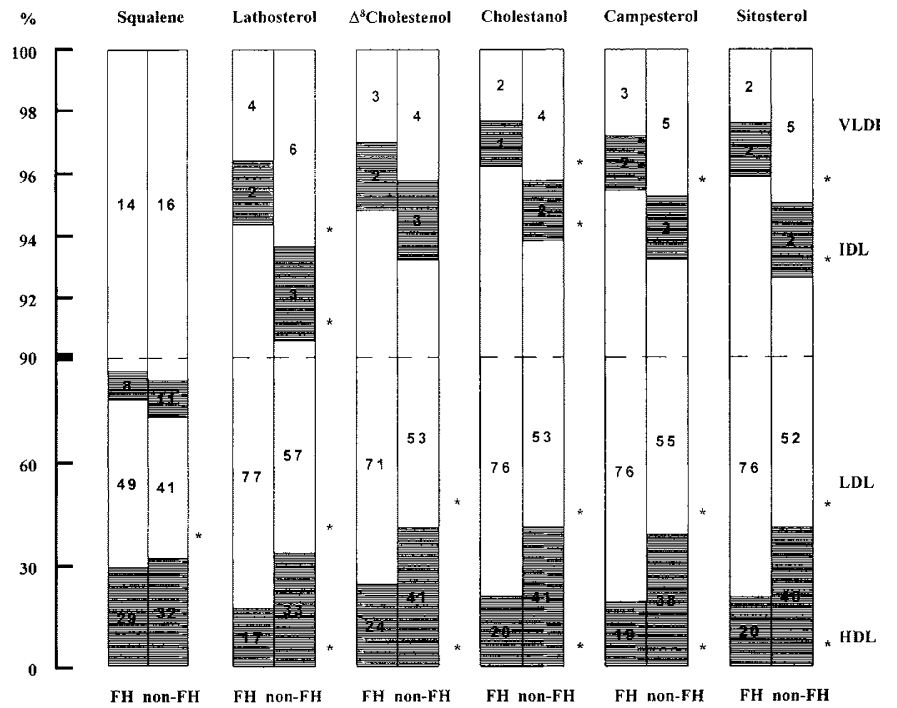

Figure 1. Percentage distribution of absolute amounts of squalene and noncholesterol sterols in lipoproteins of FH $(n=18)$ and non-FH $(n=29)$ subjects. For squalene, $n=14$ and $n=24$, respectively. Note that the ordinate scale is changed at $90 \%$. Bottom portion of the column (shaded) is HDL, the second (clear) is LDL, the third (shaded) is IDL, and the top portion (clear) is VLDL. $* p<0.05 v s$ FH.

exception of HDL, the distribution of squalene in lipoproteins differed markedly from sterols (Fig. 1).

Squalene and noncholesterol sterol concentrations. The serum concentrations of all the sterols, except $\Delta^{8}$-cholestenol, were higher in the FH than in the non-FH group (Table 3). In LDL, all the sterols and in IDL, those of desmosterol, campesterol, and cholestanol were higher in the FH than in the non-FH group. The noncholesterol sterol levels in VLDL and HDL were similar in the two groups. The squalene concentration of LDL only was higher in the FH than in the non-FH group.

Ratios of squalene and noncholesterol sterols. Despite the marked differences in sterol concentrations, the respective ratios of noncholesterol sterols were similar in the serum and in the lipoproteins of the two groups, with the exception of the high IDL lathosterol ratio in the non-FH group (Table 4). The ratios of squalene in serum, IDL, and LDL were lower in the FH than in the non-FH group.

The ratios of the precursor sterols (e.g. lathosterol versus $\Delta^{8}$-cholestenol, $r=0.664, p<0.01$ in the FH group and $r=$ $0.743, p<0.001$ in the non-FH group) and also those of the absorption markers (e.g. cholestanol versus sitosterol, $r=$ $0.532, p<0.05$ and $r=0.647, p<0.001$, respectively) were correlated with each other in the serum. In LDL and HDL, but not in VLDL and IDL, the respective correlations were mostly similar to those in the serum. In the combined group, the ratio of squalene was positively correlated with those of precursor sterols in serum, VLDL, and IDL ( $r$ ranged from 0.212 to $0.578 ; p<0.001$ ) but surprisingly positively also with the absorption markers (e.g. sitosterol $r$ ranged from 0.324 to $0.643 ; p$ ranged from 0.05 to 0.001 ). In contrast to studies in adults $(8,10)$, the precursor sterol ratios were negatively correlated with those of plant sterols and cholestanol only in LDL of FH group ( $r=-0.533$ for lathosterol versus campesterol; $p<0.05)$. 
Table 3. Concentrations of squalene and noncholesterol sterols in serum and lipoproteinst

\begin{tabular}{|c|c|c|}
\hline Variables & $\begin{array}{c}\mathrm{FH} \ddagger \\
(n=18)\end{array}$ & $\begin{array}{l}\text { Non-FH§ } \\
(n=29)\end{array}$ \\
\hline \multicolumn{3}{|l|}{ Squalene } \\
\hline Serum & $63.3 \pm 13.6$ & $50.6 \pm 3.1$ \\
\hline VLDL & $9.5 \pm 0.9$ & $11.1 \pm 1.1$ \\
\hline IDL & $5.8 \pm 0.7$ & $7.1 \pm 0.5$ \\
\hline LDL & $35.4 \pm 2.8$ & $28.0 \pm 1.5^{*}$ \\
\hline HDL & $20.1 \pm 1.2$ & $21.2 \pm 1.0$ \\
\hline \multicolumn{3}{|c|}{$\Delta^{8}$-cholestenol } \\
\hline Serum & $24.6 \pm 4.2$ & $18.2 \pm 1.6$ \\
\hline VLDL & $0.6 \pm 0.2$ & $0.4 \pm 0.1$ \\
\hline IDL & $0.4 \pm 0.1$ & $0.2 \pm 0.04$ \\
\hline LDL & $14.4 \pm 2.6$ & $6.4 \pm 0.7^{* *}$ \\
\hline HDL & $4.3 \pm 0.6$ & $5.2 \pm 0.8$ \\
\hline \multicolumn{3}{|l|}{ Desmosterol } \\
\hline Serum & $159.9 \pm 9.5$ & $84.2 \pm 3.8^{* * *}$ \\
\hline VLDL & $4.4 \pm 1.0$ & $3.6 \pm 0.7$ \\
\hline IDL & $2.5 \pm 0.4$ & $1.3 \pm 0.2 * *$ \\
\hline LDL & $119.1 \pm 7.3$ & $44.0 \pm 2.8^{* * *}$ \\
\hline HDL & $28.7 \pm 1.9$ & $34.2 \pm 4.2$ \\
\hline \multicolumn{3}{|l|}{ Lathosterol } \\
\hline Serum & $275.8 \pm 25.1$ & $165.4 \pm 9.5^{* * *}$ \\
\hline VLDL & $10.0 \pm 2.4$ & $9.0 \pm 1.6$ \\
\hline IDL & $5.2 \pm 0.8$ & $3.9 \pm 0.3$ \\
\hline LDL & $189.3 \pm 20.3$ & $79.1 \pm 5.4 * * *$ \\
\hline HDL & $37.9 \pm 2.6$ & $46.8 \pm 3.9$ \\
\hline \multicolumn{3}{|l|}{ Campesterol } \\
\hline Serum & $1050.9 \pm 113.8$ & $541.6 \pm 29.2^{* * *}$ \\
\hline VLDL & $27.8 \pm 5.6$ & $25.4 \pm 3.7$ \\
\hline IDL & $17.7 \pm 2.5$ & $11.3 \pm 1.1^{*}$ \\
\hline LDL & $813.2 \pm 113.1$ & $302.1 \pm 22.5^{* * *}$ \\
\hline HDL & $192.2 \pm 21.1$ & $220.8 \pm 17.1$ \\
\hline \multicolumn{3}{|l|}{ Sitosterol } \\
\hline Serum & $469.9 \pm 46.5$ & $266.0 \pm 15.1^{* * *}$ \\
\hline VLDL & $10.5 \pm 1.6$ & $12.5 \pm 2.1$ \\
\hline IDL & $7.8 \pm 1.1$ & $6.3 \pm 0.5$ \\
\hline LDL & $355.3 \pm 48.4$ & $143.2 \pm 10.0^{* * *}$ \\
\hline HDL & $90.9 \pm 9.4$ & $111.0 \pm 7.7$ \\
\hline \multicolumn{3}{|l|}{ Cholestanol } \\
\hline Serum & $418.2 \pm 21.1$ & $228.3 \pm 8.0^{* * *}$ \\
\hline VLDL & $9.2 \pm 1.5$ & $9.0 \pm 1.5$ \\
\hline IDL & $5.8 \pm 0.6$ & $4.1 \pm 0.3^{*}$ \\
\hline LDL & $304.6 \pm 20.8$ & $115.0 \pm 6.2^{* * *}$ \\
\hline HDL & $78.9 \pm 4.3$ & $89.2 \pm 5.7$ \\
\hline
\end{tabular}

$\dagger$ Values are mean \pm SEM (in $\mu \mathrm{g} / \mathrm{dL}$ ). The values can be converted to $\mu \mathrm{mol} / 1$ by dividing the values by 38.7 .

$\ddagger$ FH are heterozygous for familial hypercholesterolemia by DNA diagnoses.

$\S$ Non-FH have total cholesterol $<5.0 \mathrm{mM}$ and are negative for the four Finnish FH mutations.

I $n=14$ and 24 for lipoproteins of $\mathrm{FH}$ and non-FH, respectively. No recovery corrections were performed.

$* p<0.05 ; * * p<0.01 ; * * * p<0.001$ vs FH.

The ratios of the noncholesterol sterols and squalene among the different lipoproteins were compared in the $\mathrm{FH}$ and the non-FH subjects, respectively (Table 4). The squalene and lathosterol ratios were higher in the VLDL and IDL than in the LDL and HDL of both groups. In contrast, campesterol, sitosterol, and cholestanol ratios were highest in HDL. $\Delta^{8}$ Cholestenol and desmosterol were distributed almost evenly in the lipoprotein fractions of both groups. There were no marked differences between the two study groups.
Table 4. Ratios of squalene and noncholesterol sterols in serum and lipoproteinst

\begin{tabular}{|c|c|c|}
\hline Variables & $\begin{array}{c}\mathrm{FH} \$ \\
(n=18)\end{array}$ & $\begin{array}{c}\text { Non-FH } \\
(n=29)\end{array}$ \\
\hline \multicolumn{3}{|l|}{ Squalene§ } \\
\hline Serum & $23.6 \pm 4.5$ & $33.9 \pm 2.39$ \\
\hline VLDL & $161.7 \pm 30.4^{*}$ & $233.8 \pm 36.0^{*}$ \\
\hline IDL & $152.7 \pm 27.4^{*}$ & $307.1 \pm 38.6 * q$ \\
\hline LDL & $19.2 \pm 1.7$ & $35.7 \pm 2.19$ \\
\hline HDL & $47.3 \pm 3.9^{*}$ & $40.5 \pm 2.7^{*}$ \\
\hline \multicolumn{3}{|c|}{$\Delta^{8}$-cholestenol } \\
\hline Serum & $9.2 \pm 1.5$ & $12.0 \pm 1.0$ \\
\hline VLDL & $7.7 \pm 1.1$ & $6.6 \pm 1.0^{*}$ \\
\hline IDL & $8.2 \pm 1.2$ & $8.9 \pm 1.3$ \\
\hline LDL & $7.1 \pm 1.0$ & $7.9 \pm 0.9 *$ \\
\hline HDL & $9.7 \pm 1.1$ & $8.9 \pm 1.0$ \\
\hline \multicolumn{3}{|l|}{ Desmosterol } \\
\hline Serum & $60.0 \pm 2.8$ & $55.1 \pm 2.0$ \\
\hline VLDL & $50.5 \pm 4.9$ & $47.4 \pm 3.3$ \\
\hline IDL & $52.9 \pm 4.8$ & $43.7 \pm 4.9^{*}$ \\
\hline LDL & $60.6 \pm 2.3$ & $54.5 \pm 3.2$ \\
\hline HDL & $64.2 \pm 4.4$ & $60.9 \pm 5.0$ \\
\hline \multicolumn{3}{|l|}{ Lathosterol } \\
\hline Serum & $102.1 \pm 7.2$ & $108.4 \pm 5.5$ \\
\hline VLDL & $115.6 \pm 6.4^{*}$ & $137.0 \pm 18.9$ \\
\hline IDL & $109.2 \pm 5.7^{*}$ & $144.1 \pm 11.1 * \Phi$ \\
\hline LDL & $94.5 \pm 7.4^{*}$ & $96.9 \pm 4.3^{*}$ \\
\hline HDL & $84.8 \pm 5.9^{*}$ & $84.0 \pm 4.6^{*}$ \\
\hline \multicolumn{3}{|l|}{ Campesterol } \\
\hline Serum & $392.8 \pm 35.5$ & $357.5 \pm 18.5$ \\
\hline VLDL & $369.1 \pm 34.1 *$ & $339.5 \pm 17.9^{*}$ \\
\hline IDL & $394.3 \pm 36.0$ & $376.4 \pm 19.3^{*}$ \\
\hline LDL & $404.0 \pm 37.3 *$ & $368.0 \pm 20.5$ \\
\hline HDL & $414.1 \pm 37.8^{*}$ & $394.3 \pm 19.9 *$ \\
\hline \multicolumn{3}{|l|}{ Sitosterol } \\
\hline Serum & $175.9 \pm 14.1$ & $176.7 \pm 10.5$ \\
\hline VLDL & $154.4 \pm 18.8^{*}$ & $194.1 \pm 27.7$ \\
\hline IDL & $180.1 \pm 17.4$ & $218.6 \pm 10.9^{*}$ \\
\hline LDL & $176.2 \pm 14.8$ & $175.0 \pm 8.9$ \\
\hline HDL & $196.3 \pm 16.2 *$ & $202.3 \pm 11.0^{*}$ \\
\hline \multicolumn{3}{|l|}{ Cholestanol } \\
\hline Serum & $157.2 \pm 5.1$ & $151.1 \pm 5.2$ \\
\hline VLDL & $124.1 \pm 6.6^{*}$ & $123.8 \pm 7.4^{*}$ \\
\hline IDL & $129.2 \pm 5.4 *$ & $145.6 \pm 8.4$ \\
\hline LDL & $154.2 \pm 5.6$ & $141.2 \pm 4.8^{*}$ \\
\hline HDL & $173.3 \pm 5.6^{*}$ & $163.8 \pm 6.7^{*}$ \\
\hline
\end{tabular}

$\dagger$ Values are mean \pm SEM. Ratio is defined as the concentration of the particular sterol (in mmol $\times 100$ ) to the concentration of cholesterol in mol.

$\ddagger$ FH have familial hypercholesterolemia by DNA diagnoses; non-FH have total cholesterol $<5.0 \mathrm{mM}$ and are negative for the four Finnish FH mutations, $\S n=14$ and 24 for lipoproteins of FH and non-FH, respectively.

$* p<0.05$ vs serum by the paired $t$ test; $9 p<0.05$ vs FH. The values are similar as $\mu \mathrm{g} / \mathrm{mg}$.

Serum versus lipoprotein squalene and noncholesterol sterol ratios. The sterol ratios in the different lipoproteins were compared with the respective values in serum (Table 4). The ratios of $\Delta^{8}$-cholestenol and desmosterol were similar with those in serum of the FH group, but in the non-FH group, the $\Delta^{8}$-cholestenol ratios were smaller, especially in VLDL and LDL, and the desmosterol ratio was lower in IDL than in serum. The lathosterol ratios in VLDL and IDL were higher and those in HDL and LDL lower than in serum of both groups. The squalene ratios in VLDL, IDL, and HDL of the two groups were markedly higher than in the serum. The 
campesterol and cholestanol ratios were lower in VLDL (and sitosterol in VLDL and cholestanol in IDL in FH) and higher in HDL than in serum (and campesterol also in LDL in FH group) of the two groups. In the non-FH group, sitosterol and campesterol were higher in IDL than in serum.

Serum sterols in apo $\boldsymbol{E}$ phenotypes. The total and LDL cholesterol levels of the children without $\mathrm{FH}$ were higher in the subjects with the apo E-4 phenotype (4.55 \pm 0.14 and $2.59 \pm$ $0.18 \mathrm{mM}$, respectively) than in those with the combined apo E-2 and apo E-3 phenotypes $(4.07 \pm 0.11$ and $2.05 \pm 0.10$ $\mathrm{mM}$, respectively; $p<0.05)$.

Among the noncholesterol sterols, only the serum sitosterol ratio was lower in the children with the apo E-4 phenotype of the non-FH and combined groups $(n=47 ; 144 \pm 13$ and 151 $\pm 9 \times 10^{2} \mathrm{mmol} / \mathrm{mol}$ of cholesterol) than in those with other phenotypes $\left(189 \pm 13\right.$ and $186 \pm 11 \times 10^{2} \mathrm{mmol} / \mathrm{mol}$ of cholesterol; $p<0.05$ for both).

\section{DISCUSSION}

In agreement with earlier findings $(13,20)$, the serum total and LDL cholesterol levels were higher in the $\mathrm{FH}$ than non-FH children, but the values were similar in FH-Hki and FH-NK. However, noncholesterol sterols, although they exhibited markedly high concentrations in serum and LDL of $\mathrm{FH}$, showed similar ratios in serum and in the lipoprotein fractions in the two groups. Comparison of the noncholesterol sterols and squalene between serum and the lipoproteins showed that the ratios in the serum did not consistently predict those in the different lipoproteins. For example, the ratios of squalene were markedly higher in VLDL and IDL than in the serum.

In a normal population, the serum total and LDL cholesterol are related to the apo E phenotype (21), as could be observed in the children without $\mathrm{FH}$ in the present study, whereas in adult patients (22) and children with FH, this association was lacking. Among the noncholesterol sterols, only the sitosterol ratio was associated with the apo E phenotype, but only in the children without FH or in the two groups combined. The sitosterol ratios were lowest in the non-FH children with the apo E-4 phenotype, suggesting decreased cholesterol absorption. In adults (23) and children aged 1 (24) and $17 \mathrm{y}(25)$, but not at 6 (26) and $11 \mathrm{y}$ (present data), sitosterol values are higher in apo E-4 phenotype as compared with other phenotypes.

For most of the lipoproteins in the children with $\mathrm{FH}$, the noncholesterol sterol concentrations were markedly higher than in those without $\mathrm{FH}$, mainly owing to the grossly increased LDL fraction. Thus, in the FH group, approximately $75 \%$ of the noncholesterol sterols were transported by LDL versus only approximately $55 \%$ in the non-FH group. The respective values were approximately 20 and $40 \%$ in HDL, indicating that the two major lipoprotein fractions transport most of the serum noncholesterol sterols. In contrast to the noncholesterol sterols, squalene accumulated in VLDL and IDL, less so in LDL (Fig. 1). The ratios of the noncholesterol sterols, but not that of squalene, were more similar in all the lipoproteins within and especially between the two study groups. Although some comparisons of the transport of squalene and noncholesterol sterols in different lipoproteins of adult subjects were made earlier $(9,27)$, the present study is the first systematic comparison of squalene and noncholesterol sterol distribution in the different lipoproteins in general and especially in children with and without FH.

The use of the serum noncholesterol sterol ratios is recommended when large population groups are studied. However, the accumulation of squalene and lathosterol in VLDL and IDL indicates that, as compared with the lipoprotein ratios, the serum ratios reveal less sensitively changes in cholesterol metabolism. In addition to underestimation of VLDL and IDL squalene and lathosterol and HDL squalene and absorption markers, the serum ratios overestimate LDL and HDL lathosterol and plant sterols and cholestanol in VLDL. However, these perturbations were similar in the $\mathrm{FH}$ and in the non-FH groups. Accordingly, accepting time-consuming ultracentrifugation and additional gas-liquid chromatography runs, cholesterol synthesis or absorption or their changes can be detected better by measurement of noncholesterol sterols in different lipoprotein fractions than in serum.

Serum noncholesterol sterols reflect cholesterol metabolism in FH (11) as in the normal population (8). Cholesterol synthesis has been shown to be within low normal limits in $\mathrm{FH}$ adults $(1,28)$, and normal in children with $\mathrm{FH}(29,30)$, whereas cholesterol absorption efficiency is similar in adults with FH and controls (31). Accordingly, the similarity of the serum noncholesterol sterol ratios in the children with and without FH in the present study suggests that cholesterol metabolism is probably similar in the two groups, even though the squalene ratios suggest lower synthesis of cholesterol in the children with FH.

In addition to cholesterol, plant sterols and cholestanol are absorbed by the intestine in small amounts (2-10\%) (32). After absorption these sterols and those synthesized by enterocytes are partly esterified and are secreted as chylomicrons into the circulation via intestinal lymph. The chylomicron remnants are taken up by the liver, where the sterols are either secreted into the plasma via VLDL or into the bile, and the precursors may also be converted into cholesterol. Endogenous hepatic cholesterol synthesis increases the amount of synthesis marker sterols in the liver, some of which are released in VLDL, which is converted into IDL in the blood stream. This would explain the large amount of precursors, especially squalene and lathosterol, in VLDL and IDL. The positive correlation of the cholesterol precursors with the absorption sterols in VLDL and IDL and negative ones in LDL suggests that squalene and noncholesterol sterols are released into circulation from the liver in the two precursor lipoproteins. However, even though IDL is converted into LDL, the ratios of squalene and lathosterol were low in LDL, possibly as a result of the short turnover rate, shown to be only a few minutes (5). Plant sterols are eliminated slowly, although faster than cholesterol, via the biliary route $(32,33)$.

From the tissues, cholesterol and probably the absorption sterols are transported back to the liver by reverse transport, mediated by HDL, lecithin:cholesterol acyltransferase (34), cholesteryl ester transfer protein (35), and the phospholipid transfer protein (36). Lecithin:cholesterol acyltransferase es- 
terifies cholesterol, desmosterol, and sitosterol (37), and obviously plant sterols also follow in the reverse transport of cholesterol from the peripheral tissues. In fact, the high HDL ratios of the absorption marker sterols could reflect their reverse transport. Similar high plant sterol HDL ratios have been reported in adults with hypertriglyceridemia and $\mathrm{FH}$ (9, 27). An explanation for these high ratios might be a deficient transfer of these sterols from HDL to the triglyceride-rich lipoproteins by transfer proteins. However, despite higher cholesteryl ester transfer protein activity and cholesterol transfer from HDL in $\mathrm{FH}$ than in normolipidemic controls (38), the absorption marker ratios were similarly high in HDL of the two present groups. In a rat study, plant sterols were carried to the bile in HDL, suggesting that HDL contributes transport of plant sterols from the tissues to the liver and bile (39). Even though the transfer of squalene and noncholesterol sterols between different lipoproteins remains unknown, it seems to be similar in children with and without $\mathrm{FH}$.

\section{CONCLUSION}

Analysis of ratios of squalene and noncholesterol sterols to cholesterol in serum gives a picture of cholesterol synthesis and absorption in general. However, the respective ratios in different lipoproteins may predict more exactly, e.g. cholesterol synthesis and its changes because the precursor lipoproteins, VLDL and IDL, are rich in cholesterol precursors.

Acknowledgments. The technical assistance of L. Kaipiainen, P. Hoffström, A. Honkonen, R. Nissilä, and O. Ahlroos is gratefully acknowledged.

\section{REFERENCES}

1. Sodhi HD, Kudchodkar BJ, Mason DT 1980 Cholesterol metabolism in clinical hyperlipidemias. In: Paoletti R, Kritchesky D (eds) Advances in Lipid Research. Academic Press, New York, pp 107-153

2. Vuorio AF, Turtola H, Kontula K 1997 Neonatal diagnosis of familial hypercholesterolemia in newborns born to a parent with a molecularly defined familial hypercholesterolemia. Arterioscler Thromb Vasc Biol 17:3332-3337

3. Tonstad S, Joakimsen O, Stensland-Bugge E, Lere TP, Ose L, Russell D, Bonaa KH 1996 Risk factors related to carotid intima-media thickness and plaque in children with familial hypercholesterolemia and control subjects. Arterioscler Thromb Vasc Biol 16:984-991

4. Virkola P, Pesonen E, Åkerblom HK, Siimes MA 1997 Cholesterol and carotid artery wall in children and adolescents with familial hypercholesterolemia: a controlled study by ultrasound. Acta Pediatr 86:1203-1207

5. Miettinen TA 1970 Detection of changes in human cholesterol metabolism. Ann Clin Res 2:300-320

6. Miettinen TA 1969 Serum squalene and methyl sterols as indicators of cholesterol synthesis in vivo. Life Sci 8:713-721

7. Kempen HJM, Glatz JFC, Gevers Leuven JA, van der Voort HA, Katan MB 1988 Serum lathosterol concentration is an indicator of whole-body cholesterol synthesis in humans. J Lipid Res 29:1149-1155

8. Miettinen TA, Tilvis RS, Kesäniemi YA 1990 Serum plant sterols and cholesterol precursors reflect cholesterol absorption and synthesis in volunteers of a randomly selected male population. Am J Epidemiol 131:20-31

9. Tilvis RS, Miettinen TA 1986 Serum plant sterols and their relation to cholesterol absorption. Am J Clin Nutr 43:92-97

10. Miettinen TA, Tilvis RS, Kesäniemi YA 1989 Serum cholestanol and plant sterol levels in relation to cholesterol metabolism in middle-aged men. Metabolism 38:136140

11. Gylling H, Miettinen TA 1988 Serum noncholesterol sterols related to cholesterol metabolism in familial hypercholesterolemia. Clin Chim Acta 178:41-50
12. Aalto-Setälä K, Helve E, Kovanen PT, Kontula K 1989 Finnish type of low density lipoprotein receptor mutation (FH-Helsinki) deletes exons encoding the carboxyterminal part of the receptor and creates an internalization-defective phenotype. J Clin Invest 84:499-505

13. Koivisto U-M, Turtola H, Aalto-Setälä K, Top B, Frants RR, Kovanen PT, Syvänen A-C, Kontula K 1992 The familial hypercholesterolemia (FH)-North Karelia mutation of the low density lipoprotein receptor gene deletes seven nucleotides of exon 6 and is a common cause of FH in Finland. J Clin Invest 90:219-228

14. Koivisto U-M, Viikari JS, Kontula K 1995 Molecular characterization of minor gene rearrangements in Finnish patients with heterozygous familial hypercholesterolemia: identification of two common missense mutations (Gly823->Asp and Leu380->His) and eight rare mutations of the LDL receptor gene. Am J Hum Genet 57:789-797

15. Tanner JM 1969 Growth and endocrinology of the adolescent. In: Gardner L (ed) Endocrine and Genetic Diseases of Childhood. Saunders, Philadelphia, pp 19-60

16. Koivisto U-M, Hämäläinen L, Taskinen M-R, Kettunen K, Kontula K 1993 Prevalence of familial hypercholesterolemia among young North Karelian patients with coronary heart disease: a study based on diagnosis by polymerase chain reaction. J Lipid Res 34:269-277

17. Miettinen TA, Koivisto PVI 1983 Non-cholesterol sterols and bile-acid production in hypercholesterolemic patients with ileal bypass. In: Paumgartner G, Stiehl A, Gerok W (eds) Bile Acids and Cholesterol in Health and Disease. MTP Press, Boston, pp $183-187$

18. Miettinen TA 1988 Cholesterol metabolism during ketoconazole treatment in man J Lipid Res 29:43-51

19. Havekes LM, de Knijff P, Beisiegel U, Havinga J, Smit M, Klasen E 1987 A rapid micromethod for apolipoprotein E phenotyping directly in serum. J Lipid Res 28:455-463

20. Kwiterovich PO 1989 Pediatric implications of heterozygous familial hypercholesterolemia. Arteriosclerosis 9:I111-I120

21. Davignon J, Gregg RE, Sing CF 1988 Apolipoprotein E polymorphism and atherosclerosis. Arteriosclerosis 8:1-2

22. Gylling H, Kuusi T, Vanhanen H, Miettinen TA 1989 Apolipoprotein E phenotype and cholesterol metabolism in familial hypercholesterolemia. Atherosclerosis $80: 27-32$

23. Kesäniemi YA, Ehnholm C, Miettinen TA 1987 Intestinal cholesterol absorption efficiency in man is related to apoprotein E phenotype. J Clin Invest 80:578-581

24. Tammi A, Ronnemaa T, Rask-Nissilä L, Miettinen TA, Gylling H, Valsta L, Viikari J, Välimäki I, Simell O, STRIP Project 2001 Apolipoprotein E phenotype regulates cholesterol absorption in healthy 13-month-old children - the STRIP study. Pediatr Res 50:688-691

25. Kempen HJ, de Knijff P, Boomsma DI, van der Hoort HA, Gevers Leuven JA, Havekes L 1991 Plasma levels of lathosterols and phytosterols in relation to age, sex, anthropometric parameters, plasma lipids, and apolipoprotein E phenotype, in 160 Dutch families. Metabolism 40:604-611

26. Tammi A, Rönnemaa T, Miettinen TA, Gylling H, Rask-Nissilä L, Viikari J, Tuominen J, Marniemi J, Simell O 2002 Effects of gender, apolipoprotein E phenotype, and cholesterol-lowering by plant stanol esters in children; the STRIP study. Special Turku Coronary Risk Factor Intervention Project. Acta Pediatr 91:1155-1162

27. Koivisto PVI, Miettinen TA 1988 Effect of ileal exclusion on lipoprotein sitosterol in familial hypercholesterolemia. Scand J Clin Lab Invest 48:193-198

28. Bilheimer DW, Stone NJ, Grundy SM 1979 Metabolic studies in familial hypercholesterolemia: evidence for a gene dosage effect in vivo. J Clin Invest 64:524-533

29. Martin GM, Nestel P 1979 Changes in cholesterol metabolism with dietary cholesterol in children with familial hypercholesterolemia. Clin Sci 56:377-380

30. Zavoral JH, Laine DC, Bale LK, Wellik DL, Ellefson RD, Kuba K, Krivit W, Kottke BA 1982 Cholesterol excretion studies in familial hypercholesterolemic children and their normolipidemic siblings. Am J Clin Nutr 35:1360-1367

31. Connor WE, Lin DS 1974 The intestinal absorption of dietary cholesterol by hypercholesterolemic (type II) and normocholesterolemic humans. J Clin Invest 53:1062-1070

32. Björkhem I, Boberg KM 1995 Inborn errors in bile acid biosynthesis and storage of sterols other than cholesterol. In: Scriver CR, Beaudet AL, Sly WS, Valle D (eds) The Metabolic and Molecular Bases of Inherited Disease. McGraw-Hill, New York, pp 2073-2099

33. Salen G, Ahrens Jr EH, Grundy SM 1970 Metabolism of $\beta$-sitosterol in man. J Lipid Res 49:952-967

34. Glomset JA 1968 The plasma lecithins:cholesterol acyltransferase reaction. J Lipid Res 9:155-167

35. Tall A 1995 Plasma lipid transfer proteins. Annu Rev Biochem 64:235-257

36. Tollefson JH, Ravnik S, Albers JJ 1988 Isolation and characterization of a phospholipid transfer protein (LTP-II) from human plasma. J Lipid Res 29:314-339

37. Nordby G, Norum KR 1975 Substrate specificity of lecithin:cholesterol acyltransferase. Esterification of desmosterol, $\beta$-sitosterol, and cholecalciferol in human plasma. Scand J Clin Lab Invest 35:677-682

38. Inazu A, Koizumi J, Mabuchi H, Kajinami K, Takeda R 1992 Enhanced cholesteryl ester transfer protein activities and abnormalities of high density lipoproteins in familial hypercholesterolemia. Horm Metab Res 24:284-288

39. Robins SJ, Fasulo JM 1997 High density lipoproteins, but not other lipoproteins, provide a vehicle for sterol transport to bile. J Clin Invest 99:380-384 